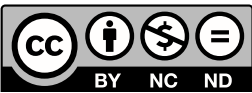

Estudos Teológicos foi licenciado com uma Licença Creative Commons Atribuição - NãoComercial - SemDerivados 3.0 Não Adaptada

http://dx.doi.org/10.22351/etv59i2.3688

\title{
LUTERo E O MATRIMÔNIO: ECONOMIA E JUSTIÇA DE Deus ${ }^{1}$
}

\author{
Luther and matrimony: economy and justice of God
}

\section{Wilhelm Wachholz ${ }^{2}$}

Resumo: O reformador Martim Lutero (1483-1546) impactou a igreja com seu combate da ética monástica medieval. Influenciada pelo neoplatonismo, a ética monástica medieval concebia o pecado como queda metafísica da alma do âmbito do espírito para o âmbito da matéria. $\mathrm{O}$ resultado desse pensamento foi a divisão da sociedade em dois estamentos e a consequente dupla ética, que acentuava a necessidade de libertação da alma da prisão do corpo. A ética monástica, que consistia na idealização do etéreo, e a consequente negação do corpo e seus desejos - jejum, celibato, abstinência sexual, castidade - desvalorizava a vida matrimonial. Lutero concebeu os esforços para a realização do ideal ascético do celibato como afronta à boa criação de Deus. O objetivo deste artigo é analisar a compreensão de Lutero sobre o matrimônio, estamento econômico criado por Deus para produção e reprodução da vida. Para fins de contextualização serão analisadas influências do neoplatonismo na ética monástica medieval e a ressignificação do matrimônio como boa criação de Deus no pensamento de Lutero. Considerando "economia" como produção e reprodução da vida, analisaremos a concepção de Lutero do pecado como germe da morte, afetando as relações ser humano-Deus e ser humano-ser humano/criação. Concluiremos o artigo com a análise do matrimônio como a afirmação do projeto original de Deus, isto é, a vida. Pelo matrimônio, homem e mulher são tornados cooperadores para justiça econômica de Deus. O artigo analisará basicamente a Preleção sobre Gênesis de Lutero (1535-1545).

Palavras-chave: Lutero. Matrimônio. Economia. Justiça.

Abstract: Martin Luther, the reformer, (1483-1546) impacted the Church with his struggle against the medieval monastic ethics. Influenced by Neoplatonism, the medieval monastic ethics conceived sin as the metaphysical fall of the soul from the sphere of the spirit to the sphere of the material. The result of this thinking was the division of society into two estates and the resulting double ethics, which accentuated the need for the liberation of the soul from the prison of the body. The monastic ethics, which consisted in the ideation of the ethereal and the consequential negation of the body and its desires - fasting, celibacy, sexual abstinence, chastity - devalued matrimonial life. Luther believed the efforts to realize the ascetic ideal of celibacy to

1 O artigo foi recebido em 06 de junho de 2019 e aprovado em 18 de novembro de 2019 com base nas avaliações dos pareceristas ad hoc.

2 Doutor. Faculdades EST, São Leopoldo, RS. E-mail: wachholz@est.edu.br 
be an affront to the good creation of God. The goal of this article is to analyze Luther's understanding of matrimony as an economic estate created by God for the production and reproduction of life. For means of contextualization, influences of Neoplatonism on the medieval monastic ethics will be analyzed as will also the resignification of matrimony as the good creation of God. Considering "economy" as the production and reproduction of life, we will analyze Luther's conception of sin as the seed of death affecting the relations human beings-God and human being-human being/creation. We will conclude the article with the analysis of matrimony as the affirmation of the original project of God, that is, life. Through matrimony man and woman become cooperators in the economic justice of God. The article will analyze basically Luther's Lecture on Genesis (1535-1545).

Keywords: Luther. Matrimony. Economy. Justice.

\section{Introdução}

A palavra "economia" abrange, em seu sentido original, os meios de sustentação (produção) e propagação (reprodução) da vida. A cultura moderna relegou o primeiro ao âmbito público e o segundo ao âmbito privado da vida. O reformador protestante Martim Lutero (1483-1546) concebe a economia em unidade como produção e reprodução da vida. A produção diz respeito aos meios que visam à sustentação da vida e à reprodução, à sexualidade e multiplicação da vida. Por essa razão, Lutero compreende a economia não como "mercado", mas como a complexidade do "governo doméstico" de produção e reprodução. No âmbito da economia, homem e mulher são, pelo matrimônio, cooperadores de Deus em favor da vida. ${ }^{3}$

A concepção de economia como produção e reprodução levou Lutero a buscar a superação do dualismo neoplatônico de matéria e espírito, o qual, mediante o pensamento de Agostinho, entre outros, havia encontrado eco no sistema doutrinário católico-romano medieval. ${ }^{4}$ Por influência de Agostinho, a tradição bíblica sobre pecado foi colocada em conexão com a doutrina neoplatônica da queda metafísica da alma do âmbito do espírito para o âmbito da matéria. $\mathrm{O}$ resultado desse pensamento foi a divisão da sociedade em dois estamentos e a consequente dupla ética, que acentuava a necessidade de libertação da alma da prisão do corpo mediante o aperfeiçoamento da vida espiritual. Por conseguinte, a ética monástica consistia, de um lado, na idealização do etéreo e, por outro lado, na negação do corpo e seus desejos e prazeres. Jejum, celibato, abstinência sexual eram pregados como conselhos para salvar a alma das paixões da carne. ${ }^{5}$

3 WESTHELLE, Vítor. Poder e Política - incursões na teologia de Lutero. In: HELMER, Christine. Lutero: um teólogo para tempos modernos. São Leopoldo: Sinodal, 2013. p. 317, 322-323.

4 Forell identifica "influências do paganismo no campo da ética" no contexto medieval. O resultado desse paganismo era o empenho egocêntrico por méritos. Ou seja, na radicalidade, tratava-se de uma ética baseada no amor-próprio. FORELL, George W. Fé Ativa no Amor. Porto Alegre: Concórdia; São Leopoldo: Sinodal, 1977. p. 66-78.

5 DEIFELT, Wanda. Da cruz à árvore da vida: epistemologia, violência e sexualidade. In: NEUENFELDT, Elaine; BERGESCH, Karen; PARLOW, Mara (Orgs.). Epistemologia, Violência e Sexualidade. Olhares 
Teológica e filosoficamente, Lutero combateu a concepção que opõe pecado e santidade a partir do princípio neoplatônico de matéria e espírito, que incidia sobre a desvalorização do matrimônio. Segundo Lutero, o ser humano foi criado por Deus para viver a partir da fé. A fé, por sua vez, não exclui, em perspectiva ascética e monástica, mas inclui vivência na história e no mundo material. Salvação, para Lutero, não consiste na libertação da matéria e da corporalidade, mas libertação da escravidão do diabo e do pecado. ${ }^{6}$ Nessa perspectiva, o reformador concebeu os esforços para a realização do ideal ascético do celibato como afronta à boa criação de Deus.

\section{Matrimônio e dualismo platônico}

No escrito À nobreza cristã da nação alemã (1520), Lutero já havia criticado o celibato, afirmando ser ele uma lei do papa e não de Deus. Defendeu que religiosos e religiosas deveriam ter liberdade ao matrimônio. ${ }^{7}$ Segundo Lutero, Deus criou o ser humano e o colocou no mundo material, e sob essas condições lhe caberia viver. Toda tentativa de uma vida sob o princípio da separação de matéria e espírito seria, de antemão, fracassada. Dever-se-ia associar antes a alma com carne do que com corpo, pois é na alma que se encontra a origem do pecado. ${ }^{8}$

Carne e espírito não se deve entender aqui como se a carne fosse apenas aquilo que se refere à impudicícia, e o espírito, o que tange a interioridade do coração. Na realidade, Paulo chama de carne, como também Cristo o faz em Jo 3[.6], a tudo que é nascido da carne, a pessoa inteira, com corpo e alma, a razão e todos os sentidos, isto pelo motivo de que tudo nela procura pela carne. Cabe saber chamar de "carnal" também àquele, portanto, que, sem a posse da graça, muito inventa, ensina e conversa sobre altos assuntos espirituais, como o podes aprender com as "obras da carne" Gl 5[.19ss.], onde ele [Paulo] também chama a heresia e o ódio de "obras da carne"; e, em Rm 8[.3] ele diz

do II Congresso Latino-Americano de Gênero e Religião. São Leopoldo: Sinodal; EST, 2015. p. 13-30. Disponível em: <http://www.est.edu.br/downloads/ppg/bibliografia/Epistemologia_Violencia_ Sexualidade.pdf>. Acesso em: 24 abr. 2019; PINOMAA, Lennart. Sieg des Glaubens; Grundlinien der Theologie Luthers. Göttingen: Vandenhoeck \& Ruprecht, 1964. p. 181-182, JUNGHANS, Helmar. Temas da Teologia de Lutero. São Leopoldo: Sinodal, 2001. p. 52, 74, 76.

6 PINOMAA, 1964, p. 182; ASENDORF, Ulrich. Lectura in Biblia; Luthers Genesisvorlesung (1535-1545). Göttingen: Vandenhoeck \& Ruprecht, 1998. p. 436.

7 LINDBERG, Carter. As Reformas na Europa. São Leopoldo: Sinodal, 2001. p. 122-123. O reformador Felipe Melanchthon (1497-1560) também se manifestou nessa direção, afirmando que a Bíblia e a tradição da igreja primitiva apoiavam matrimônio de religiosos e religiosas. Outro reformador de Wittenberg, André Bodenstein von Karlstadt (cerca de 1480-1541), igualmente argumentou em favor do matrimônio de religiosos, inclusive com mais radicalidade. Com base em $1 \mathrm{Tm} 3.2$ e 5.9, Karlstadt afirmava que todos os sacerdotes deveriam se casar e que, inclusive, nenhuma pessoa deveria tornar-se freira ou monge abaixo de 60 anos de idade e, quem estivesse em mosteiros com idade inferior a 60 anos deveria ter liberdade de viver em matrimônio. Lutero combateu a concepção de Karlstadt, afirmando que ele estaria reproduzindo a mesma lógica medieval, desvirtuando a liberdade ao transformá-la em uma nova lei. LINDBERG, 2001, p. $122-123$.

8 PINOMAA, 1964, p. 182. 
que através da carne a lei é enfraquecida. Aí não se refere à impudicícia, mas a todos os pecados, sobretudo, porém, à falta de fé, que é o mais espiritual dos vícios. ${ }^{9}$

Para Lutero, o pecado de origem ${ }^{10}$ está na alma - e não no corpo! - do ser humano. A pretensão de libertação da alma das amarras do corpo não representa libertação do pecado. O pecado caracteriza-se pelo afastamento do ser humano de Deus, pretendendo viver de forma egocentrada e autossuficiente, portanto sem fé-confiança. A concepção antropológica dicotômica ou tricotômica (espírito, alma e corpo) não faz sentido na teologia de Lutero. O ser humano está integralmente implicado no pecado - não somente seu corpo! Igualmente, o ser humano está implicado em sua totalidade no que diz respeito à salvação. A origem do pecado não pode ser localizada na vida física externa. O pecado é sempre também corrupção da alma. E isso fica evidenciado de forma especial na própria tentativa de realizar o ideal de castidade sexual. $\mathrm{O}$ ser humano pode até manter pureza de seu corpo pela castidade sexual, mas isso não é garantia de incorruptibilidade da alma. A vida monástica, portanto, não garante libertação do pecado. Todo o ser humano é "carne", portanto o pecado o escraviza em sua totalidade. Desta forma, o ser humano se encontra integralmente diante da ira de Deus. Não há nele uma força divina (virtus) ou centelha divina (synteresis) que lhe permita a "iniciativa" perante Deus. Pelo contrário, o ser humano somente se torna bom sob a ação graciosa do Espírito Santo de Deus. ${ }^{11}$

Deus criou o mundo material, incluso o ser humano corpóreo, e mantém commercium no tempo e com a matéria, não se limitando à esfera "espiritual". A "carne", no sentido de matéria, não está relegada ao domínio ilimitado de Satanás. Por isso a própria sexualidade não deve ser repudiada e desprezada. Afirmar que o ser humano nasce em pecado (Salmo 51.7) não permite concluir que as relações sexuais são $a$ priori pecado. Nesse sentido, Lutero afronta concepções que pretendem fundamentar o matrimônio como legalização do impulso para o pecado. Pelo contrário, a dignidade do matrimônio está no fato de que o encontro dos gêneros ${ }^{12}$ é ordenado pelo próprio Deus. Por ser ordenação de Deus, ele santifica o matrimônio e o constitui como tesouro e dádiva. ${ }^{13}$

9 LUTERO, Martinho. Prefácio à Epístola de S. Paulo aos Romanos. In: Obras Selecionadas. São Leopoldo: Sinodal; Porto Alegre: Concórdia, 2003. v. 8, p. 133-134.

${ }^{10}$ Concebemos aqui "pecado original" em perspectiva de "pecado de origem". Para Lutero, "pecado de origem" não tem conotação de "pecado hereditário", em perspectiva biológica e, portanto, como transmissão do pecado no ato reprodutivo (sexualidade), mas como início histórico, mais precisamente como determinação básica de toda a pessoa. BAYER, Oswald. A Teologia de Martim Lutero; uma atualização. São Leopoldo: Sinodal, 2007. p. 137-139.

11 PINOMAA, 1964, p. 182-183. Sobre synteresis em Lutero, veja LOEWENICH, Walther von. A Teologia da Cruz de Lutero. São Leopoldo: Sinodal, 1988. p. 46-54.

12 O conceito "gênero", como tal, não é conhecido por Lutero. Nossa utilização aqui parte do pressuposto de que gênero, diferentemente de sexo, é definido socialmente e tem variabilidade de espaços e tempos sociais. Nesse sentido, a ênfase da cooperação de homem e mulher na sociedade mediante o matrimônio permite aproximação com o conceito de gênero. Veja LINDBERG, 2001, p. 431.

13 PINOMAA, 1964, p. 183. 
Lutero rompe com a concepção de matrimônio que contrapõe corporalidade e espiritualidade, como ressaltamos acima. Sexualidade e ascese não mais são concebidas em paralelo com pecado e santidade. Por essa razão, para responder a questão se há alguma diferença fundamental entre fornicação e matrimônio, Lutero insiste que a resposta está na Palavra: a pessoa que vive o matrimônio se submeteu à ordem de Deus, expressa em sua Palavra, enquanto a pessoa adúltera satisfaz seus impulsos em contradição com a palavra de Deus. Mas, por essa mesma razão, não somente o adúltero conduz vida impura; sem a palavra de Deus, também o matrimônio é impuro. ${ }^{14}$

Lutero concebe que o divino reside na baixeza, nas formas comuns da vida, no cotidiano, naquilo que é desprezado e insignificante. E exatamente por ser desprezado, Deus santifica pessoas por meio do matrimônio. ${ }^{15} \mathrm{O}$ matrimônio pertence ao conjunto daquilo que Deus criou e "viu que era bom". O diabo age para separar Adão e Eva e o faz, segundo Lutero, porque "não tem muita afinidade com a vida matrimonial, visto que é obra de Deus e sua boa vontade"16.

A ética monástica medieval orientava-se para o transcendental, desprestigiando a dimensão natural da vida, colocando o imperativo da superação da "fraqueza da carne" por meio do ideal de vida ascética. Para Lutero, o ideal celibatário monástico medieval é expressão de autojustificação egoísta diante de Deus. ${ }^{17}$ As verdadeiras mortificações “[...] não acontecem em lugares desertos, fora da sociedade dos seres humanos, mas no próprio domicílio [economia] e no Estado [política] [...]"18.

Como já ressaltamos acima, Lutero concebeu o matrimônio no âmbito da criação de Deus e o deslocou para o cotidiano da vida humana. O deslocamento do matrimônio para o cotidiano visou, no pensamento de Lutero, enfatizar a dimensão da coexistência e cooperação humana. Seu argumento não era o da "fraqueza da carne" ou da falência da vida ascética, mas afirmação do matrimônio e da sexualidade a partir da vontade de

14 PINOMAA, 1964, p. 184.

15 PINOMAA, 1964, p. 184. Em seu escrito O Magnificat, Lutero afirma que Deus santifica o ser humano ao "tocá-lo". Ao tocar o ser humano, torna-o "oficina na qual ele trabalha", o que resulta serem as obras de Deus por meio do ser humano santificadas. LUTERO, Martinho. O Magnificat; traduzido e explicado pelo Dr. Martinho Lutero, agostiniano. In: Obras Selecionadas. São Leopoldo: Sinodal; Porto Alegre: Concórdia, 1996. v. 6, p. 51-52.

${ }^{16}$ LUTERO, Martinho. Da Vida Matrimonial. In: Obras Selecionadas. São Leopoldo: Sinodal; Porto Alegre: Concórdia, 1995. v. 5, p. 175. Ver também BAYER, 2007, p. 104.

17 Lutero combate a expressão escolástica facere quod in se est ("fazer o que está ao seu alcance"), no sentido da salvação ser um processo que acontece dentro da pessoa, à medida que se aperfeiçoa, isto é, se tornando justa diante de Deus por meio da realização de obras justas. A incerteza, contudo, é gerada pela própria expressão, afinal, como saber que a pessoa fez o melhor de si para merecer a graça? LINDBERG, 2001, p. 81-82.

18 LUTERO, Martinho. Preleção sobre Gênesis. In:

. Obras Selecionadas. São Leopoldo: Sinodal; Porto Alegre: Concórdia; Canoas: Ulbra, 2014. v. 12, p. 476. Veja também LOEWENICH, 1988, p. 121. Do livro Vitae Patrum Lutero resgata o exemplo segundo o qual um eremita se retirara para o deserto com seu filho único. Ante o choro insistente da criança, o eremita quis jogá-lo num rio e afogá-lo. Segundo Lutero, essa história não pode ser comparada à de Abraão e seu filho Isaque; caso o eremita tivesse afogado seu filho, teria se tornado assassino, pois não teria sido uma obra em fé e obediência a Deus, mas obra autoescolhida. A história do eremita é, para Lutero, exemplo de autojustificação e egocentrismo. LUTERO, 2014 , p. 487-489, 530 . 
Deus e da ordem de sua criação. Por isso Lutero combate o celibato - quando não houver explícita vocação! - como contemplação egocêntrica e enaltece o matrimônio como chance dada por Deus para exercício de amor e serviço ao próximo. ${ }^{19}$

A teologia medieval distinguia entre mandamentos e conselhos. Segundo essa concepção, caberia à pessoa cristã obedecer aos mandamentos divinos; a observância dos conselhos, por sua vez, concederia méritos adicionais..$^{20} \mathrm{O}$ celibato era considerado meritório diante de Deus. Desenvolvendo a concepção de sacerdócio geral de todas as pessoas que creem, Lutero defendia que o celibato - nem matrimônio! - não deve ser lei nem concebido como meritório diante de Deus. Celibato - e matrimônio! - verdadeiro é aquele que é "pro-vocado" (provocare), ou seja, chamado para serviço. E, neste caso, a vocação ao celibato não difere da vocação de um agricultor, professor, jurista. Toda vocação, inclusive celibato ou vida monástica, somente é agradável a Deus quando não é fruto de autoescolha egoísta, mas vocação a serviço do amor ao próximo. ${ }^{21}$ Nesse espírito, Lutero chega a afirmar, por exemplo, que "o matrimônio não consiste apenas em dormir com uma mulher - qualquer um pode fazer isso! -, mas sim em cuidar do lar e criar os filhos" ${ }^{22}$.

Lutero prezou pelo estado matrimonial, não em perspectiva romântica, mas "pragmática", isto é, como chamado ao serviço. ${ }^{23} \mathrm{O}$ pragmatismo não exclui o afeto na relação matrimonial. $\mathrm{O}$ afeto, contudo, não é o fundamento do matrimônio. O seu fundamento é o preceito de Deus, a saber, que foi instituído, ordenado por Deus, por meio do qual homem e mulher servem, cooperam. ${ }^{24}$ Três dimensões desse pragmatismo podem ser identificadas em seu pensamento sobre matrimônio: refúgio e medicina (necessidade enquanto natureza sexual) ${ }^{25}$, educação de filhos e conservação da espé-

19 PINOMAA, 1964, p. 186; JUNGHANS, 2015, p. 22.

20 Já na igreja antiga podemos identificar a defesa de abstinência sexual, celibato e virgindade perpétua como modelo de vida cristã. Como exemplo, citemos Jerônimo (347-420), que, comparando virgindade, viuvez e casamento, atribuiu peso numérico meritório de 100 para a virgindade, 60 para a viuvez e 30 para o matrimônio. Ainda segundo Jerônimo, enquanto o matrimônio enche a terra, a virgindade enche o céu. DEIFELT, 2015, p. 23.

${ }^{21}$ LINDBERG, 2001, p. 123-124.

${ }^{22}$ LUTERO apud LINDBERG, 2001, p. 127, 430.

${ }^{23}$ O "pragmatismo" de Lutero sobre matrimônio se torna mais evidente a partir de 1525, quando se casa com a ex-freira Catarina von Bora. Com seu casamento, aproxima-se dos problemas econômicos do cotidiano, típicos de uma sociedade de cidade pequena. Não se pode, por exemplo, menosprezar os impactos em seu pensamento das atividades de sua esposa na administração de sua casa. Por diversas vezes, Lutero se queixava sobre os altos preços, e essa experiência o orientou em seus escritos sobre ética econômica. PRIEN, Hans-Jürgen. Luthers Wirtschaftsethik. Göttingen: Vandenhoeck \& Ruprecht, 1992. p. 53.

24 DIETZ, Martin Timóteo. Amor em Lutero; Perspectivas a partir da explicação dos mandamentos. In: BRÍGIDO, Maria Aparecida da Silveira; HERBES, Nilton Eliseu; HEIMANN, Thomas (Orgs.). Amor em Relação; Reflexões sobre o amor numa perspectiva multidisciplinar. São Leopoldo: Sinodal; EST, 2018. p. 85.

${ }^{25}$ Essa "necessidade natural" não deveria ser compreendida em Lutero negativamente, por exemplo, "força anárquica e incontrolável", mas positivamente, a saber, a sexualidade como boa criação de Deus, de forma que o prazer sexual é legítimo para homem e mulher. Por isso, diferentemente da igreja medieval, por exemplo, que tolerava e justificava a necessidade de prostitutas como meio de "descarga" do desejo sexual e bordéis como meios para evitar males maiores do adultério e do estupro, Lutero afirmou que esse "remédio" seria pior do que a "doença" (neste caso em particular, o desejo sexual masculino). LINDBERG, 2001, p. 431-432. 
cie (reprodução). ${ }^{26}$ A concepção "pragmática" de matrimônio de Lutero está orientada para o serviço ao próximo, a partir do sacerdócio geral de todas as pessoas que creem. Aliás, o reformador percebe no matrimônio vestígios do que teria sido a relação entre Adão e Eva no jardim do Éden. Matrimônio fomenta consciência de pertencimento mútuo, de comunhão humana, de serviço. Pela mutualidade, inclusa a sexualidade, o ser humano realiza e se realiza como criatura de Deus em perspectiva de relações éticas. ${ }^{27}$

\section{Matrimônio e economia: produção e reprodução da vida}

A antropologia de Martim Lutero caracteriza-se pela palavra-chave coram, que expressa sentido espacial e temporal de "diante de", "face a", ou ainda "na presença de". Para Lutero, coram expressa a relação do ser humano para fora de si. Mais do que isso, expressa a relação de um outro para si, de ser olhado, observado de fora. Trata-se da minha presença determinada pela presença de outra pessoa. Disso resulta a afirmação da presença do outro em mim e de minha presença nesse outro. A minha existência é determinada diante de um outro, isto é, face a um outro. ${ }^{28}$

O coram é definido, fundamentalmente, como coram Deo, ou seja, diante de Deus. Essa relação é fundante a partir da fé-confiança. Dessa relação fundante resultam outras três relações coram: a existência diante de si mesmo (coram seipso), a existência face aos seres humanos (coram hominibus) e a existência face ao mundo (coram mundo). A existência diante de Deus (a partir da fé), de alguma forma, funde a existência face aos seres humanos e ao mundo (pelo amor). O princípio coram, portanto, indica que a existência humana se dá fora de si mesma, extra se, diante de Deus e toda a criação. A existência diante de Deus engloba a existência do mundo e vice-versa. ${ }^{29}$ Portanto do coram Deo resulta a ética cristã da pessoa, que “[...] faz justiça a Deus pela fé e, também pode, agora, fazer justiça ao mundo através do amor"

Lutero concebe a ética cristã em conexão com a doutrina dos três estamentos ou âmbitos da vida (ecclesia, oeconomia e politia). ${ }^{31}$ Os três estamentos são os âmbitos ou espaços da realização ética da pessoa cristã no sentido de co-ser-humanidade (coram). A realização ética ocorre no âmbito da vida social, com espaços determinados, como, por exemplo, igreja e escola, casa e pátio, prefeitura e palácio, nos quais pessoas exercem funções públicas. Os três âmbitos da vida precisam, ainda que distintos, encontrar ponto de referência e unidade a partir da palavra de Deus e seus mandamentos. ${ }^{32}$

\footnotetext{
26 PINOMAA, 1964, p. 184.

${ }^{27}$ Lutero, por exemplo, defendeu o direito de uma mulher ter relações sexuais fora do matrimônio em caso de impotência do marido, isto é, de não satisfação sexual. LUTERO, 1995, p. 163.

28 EBELING, Gerhard. O Pensamento de Lutero. São Leopoldo: Sinodal, 1988. p. 152-155.

29 EBELING, 1988, p. 156-158.

${ }^{30}$ EBELING, 1988, p. 159. Ver também FORELL, 1977, p. 79-109; DIETZ, 2018, p. 82-84.

31 Em sua Preleção sobre Gênesis, Lutero identifica os três estamentos como "o governo, a economia [do lar] e a Igreja." LUTERO, 2014, p. 231. Também podem ser encontradas referências aos três estamentos em Lutero como sendo o estamento de defesa, o magisterial e o alimentício. Mas Lutero frequentemente também define como estamento as profissões específicas. JUNGHANS, 2001, p. 75.

32 PRIEN, 1992, p. 164, 166; JUNGHANS, 2001, p. 52, 75.
} 
O decálogo é concebido por Lutero a partir dos três estamentos, atribuindo ao status ecclesiasticus os primeiros dois mandamentos, ao status oeconomicus, os mandamentos quarto, sexto, sétimo, nono e décimo e ao status politicus, os mandamentos quinto e oitavo. Cada um dos estamentos se relaciona com Deus à medida que o ser humano, em cada um dos três âmbitos da vida, é cooperador com Deus. O status oeconomicus, em particular, adquire em Lutero caráter de serviço em favor do coletivo, isto é, visando suprir as necessidades fundamentais para a "vida da casa", portanto em conexão com a ecologia da criação de Deus. ${ }^{33}$ A criação é dádiva de Deus, pela qual Deus supre e garante a vida (produção e reprodução), e o ser humano, em seu status oeconomicus como cooperador de Deus, testemunha a economia justa e solidária de Deus para com o seu próximo e toda a criação. ${ }^{34}$

O quarto mandamento serve para Lutero ampliar sua concepção do estamento doméstico (oeconomia), no sentido de que a autoridade dos pais é estendida e abrange a autoridade espiritual e secular. Concretamente isso significa que o "estamento matrimonial" abrange o "estamento doméstico" em perspectiva de status oeconomicus e, por conseguinte, abarca deveres dos pais em relação (coram) aos filhos, dos senhores, agricultores, artesãos em relação aos servos e empregados e, inclusive, dos governantes em relação aos funcionários públicos. O critério do status oeconomicus (como também ecclesiasticus e politicus), portanto, é o serviço ao próximo, evidenciando-se como estamento-para-o-próximo. ${ }^{35}$ Segundo o reformador,

Toda a vida é dividida em três estamentos: vida doméstica, vida pública, vida eclesiástica. Qualquer que seja o estamento em que te encontrares, se és marido, funcionário do Estado ou professor da Igreja - examina se satisfizeste plenamente tua vocação e se não há necessidade de pedir perdão por negligência, indiferença ou impaciência ${ }^{36}$.

Economia, enquanto "procriação" (reprodução) e "preservação" (produção) da vida, pressupõe colaboração de homem e mulher. ${ }^{37}$ A mulher foi feita "[...] parceira para a procriação e a conservação da espécie" ${ }^{38}$. Por essa razão, Lutero combateu veementemente o celibato, por ser "[...] fonte de insultos contra o sexo feminino" 39 . Os celibatários ignoram a coabitação, pelo fato de não "[...] cuidarem dos assuntos familiares, gerarem e educarem juntos os filhos" ${ }^{40}$.

Não só existem aqueles que creem que é sábio insultar o [outro] sexo e rejeitar o casamento, mas também os que abandonam as esposas e lançam de si toda a preocupação

\footnotetext{
33 PRIEN, 1992, p. 167.

34 WESTHELLE, 2013, p. 322, 328.

35 PRIEN, 1992, p. 165-166, 169-170.

${ }^{36}$ LUTERO, 2014, p. 448.

37 LUTERO, 2014, p. 146; JUNGHANS, 2001, p. 52-53.

38 LUTERO, 2014, p. 150.

39 LUTERO, 2014, p. 148. Interpretando Gn 3.16, Lutero denuncia que "[...] chegou-se ao ponto de homens ímpios preferirem fornicar a casar". LUTERO, 2014, p. 217.

${ }^{40}$ LUTERO, 2014, p. 159.
} 
com os filhos. Eles destroem com sua improbidade e perversidade o edifício [a mulher] de Deus e, realmente, são monstros abomináveis da natureza. Por isso, obedeçamos à Palavra de Deus e reconheçamos em nossas esposas um edifício do Senhor. Por intermédio delas, não só é edificada a casa através da procriação e de outros serviços necessários na organização doméstica, mas também porque os próprios maridos são edificados por elas, para os quais elas são como ninho ou habitação para onde eles se dirigem, a fim de passar o tempo e viver com alegria. ${ }^{41}$

No pensamento de Lutero, a justiça econômica está estreitamente ligada à dignificação do matrimônio como "[...] um modo de vida divino, isto é, [que] foi ordenado por Deus mesmo" ${ }^{2}$. Por essa razão, é necessário “[...] tornar o casamento novamente respeitado mediante a Palavra de Deus e celebrá-lo com os merecidos louvores $[. . .]^{\prime 43}$. A igualdade entre marido e esposa - Lutero afirma que ambos não diferem "[...] em nenhum outro aspecto senão no sexo"44 -, e considerando serem marido e esposa o núcleo central da organização doméstica/econômica, é a base da justiça econômica.

Lutero evoca o conceito de vocação em oposição às tradições humanas, em particular àquelas impostas pela igreja medieval com relação a celibato, viuvez e virgindade. Celibato somente é legítimo quando provém da vocação; como imposição, é afirmação de justiça de obras autoescolhidas que resultam em morte e não justiça concedida, doada e que resulta em vida. Em outras palavras, o estado de celibato, viuvez, virgindade somente é legítimo se não “[...] comprometer a economia doméstica e o Estado. Pois estes são estamentos de vida ordenados e instituídos por Deus"45.

Para Lutero, contra a tendência medieval de negar a sexualidade em perspectiva moralista, é necessário recuperar a própria sexualidade na perspectiva da vida: "[Deus] não condena a procriação em si, mas o abuso, que procede do pecado original. Pois a majestade real, a sabedoria, as riquezas, as forças do corpo são coisas boas; tê-las também é bom, pois são concedidas aos seres humanos por Deus" ${ }^{\text {"46. }}$

Deus criou Adão e Eva em justiça original. A justiça original é perdida quando o diabo extirpa de Adão e Eva a Palavra e a confiança, instituindo a incredulidade e a dúvida - "Para que, talvez, não morramos" (Gn 3.3-4). ${ }^{47} \mathrm{O}$ diabo o faz imitando Deus, segundo Lutero. A imitação de Deus pelo diabo tem por finalidade a invenção pelo ser humano de um outro deus. Referindo-se ao casamento, Lutero ataca o "monge", denunciando-o como idólatra por inventar um novo deus.

${ }^{41}$ LUTERO, 2014, p. 160. Veja também LINDBERG, 2001, p. 430.

${ }^{42}$ LUTERO, 2014, p. 161. Veja também DIETZ, 2018, p. 85.

${ }^{43}$ LUTERO, 2014, p. 161; JUNGHANS, 2001, p. 74-75.

${ }^{44}$ LUTERO, 2014, p. 163. Interpretando Gn 3.16-19, Lutero afirma que a mulher é "[...] parceira de todas as dádivas de Deus, em nenhum sentido inferior ao homem”. LUTERO, 2014, p. 219.

${ }^{45}$ LUTERO, 2014, p. 437.

${ }^{46}$ LUTERO, 2014, p. 256.

${ }^{47}$ Lutero destaca duas tentações que decorrem da dúvida suscitada por Satanás a Adão e Eva: 1) Que Deus não teria dito, portanto, seria possível comer dos frutos da árvore e, 2) Que Deus permitiu possuir tudo, o que incluiria os frutos dessa árvore. LUTERO, 2014, p. 177. 
O pecado de origem caracteriza-se pela ação diabólica de Satanás, separando Adão e Eva de Deus, tornando-se eles incrédulos diante do Deus (três primeiros mandamentos).$^{48} \mathrm{O}$ diabo faz exatamente isso, "[...] nos tornar sábios contra e acima da Palavra de Deus [...]"49. A incredulidade é, por essa razão, a origem de todos os pecados. Ela é o germe da própria morte.

O pecado de origem inaugura o "germe" da morte, atingindo o centro da economia humana: a reprodução e a produção da vida. Encontrado por Deus, Adão se envergonha, o que atesta a perda da confiança em Deus. Adão e Eva fazem cintos para cobrir a parte do corpo "[...] mais nobre [... da] atividade da procriação" procriação - Lutero a entende como a que "conserva a espécie" ${ }_{51}$ (reprodução) - é corrompida. Pecado, portanto, não tem conotação moral, mas é, fundamentalmente, a força da morte. Por isso Lutero associa o diabo com a morte: "Satanás é o pai da mentira e um homicida [...] foi homicida desde o início [...]". ${ }^{52}$ Antes do pecado, os corpos eram mais saudáveis e mais longevos. ${ }^{53}$ "Assim, a queda de Adão deu-se da vida para a morte, da saúde para a doença." ${ }^{54}$ Por isso, com a queda no pecado, "[...] desde o útero da mãe, começamos a morrer"

As marcas do pecado são também carregadas pelo ser humano em sua vestimenta. Deus mesmo veste Adão e Eva, não com folhas, mas com peles de animais mortos, como marcas da morte e da perda da "suprema felicidade" e da queda na "extrema desgraça e miséria" 56 . A pele com que é coberto deve despertar o ser humano para a "imagem perdida de Deus e comece a odiar [...] o pecado [...]"57. Contrariamente, contudo, o ser humano se veste de luxo, evidenciando sua "loucura"58.

O pecado também afeta as relações humanas e o relacionamento do ser humano com a criação, na medida em que "todos se empenham unicamente para acumular riquezas e oprimir os outros por meio de enganos, fraudes e injúrias, para seu próprio enriquecimento" ${ }^{59}$. E "geralmente, as pessoas são induzidas ao pecado por causa do prazer ou de alguma vantagem" ${ }^{\prime 60}$.

O pecado, finalmente, afeta o ser humano na sua relação diante (coram) de Deus. Ele não reconhece sua condição de pecado. Pelo contrário, tenta negar ou justificar/defender seu pecado perante Deus e o próprio ser humano, a exemplo de Adão.

${ }^{48}$ LUTERO, 2014, p. 166-173.

${ }^{49}$ LUTERO, 2014, p. 184.

${ }^{50}$ LUTERO, 2014, p. 189.

${ }^{51}$ LUTERO, 2014, p. 190.

${ }^{52}$ LUTERO, 2014, p. 234; ASENDORF, 1998, p. 78. Lutero está fazendo referência ao Evangelho de João 8.44.

${ }_{53}$ LUTERO, 2014, p. 223.

${ }^{54}$ LUTERO, 2014, p. 233.

${ }_{55}^{55}$ LUTERO, 2014, p. 212; ASENDORF, 1998, p. 77.

${ }^{56}$ LUTERO, 2014, p. 237.

${ }^{57}$ LUTERO, 2014, p. 239.

${ }^{58}$ LUTERO, 2014, p. 238.

${ }^{59}$ LUTERO, 2014, p. 458.

${ }^{60}$ LUTERO, 2014, p. 459. No Debate de Heidelberg, Lutero denuncia o acúmulo de riqueza como "hidropisia da alma", no sentido "quanto mais bebe, mais sede tem". LUTERO, Martinho. Debate de Heidelberg. In: . Obras Selecionadas. São Leopoldo: Sinodal; Porto Alegre: Concórdia. 1987. v. 1, p. 51. 
A justiça de Adão e Eva caídos no pecado evidenciou-se como autojustificação, ou como "aparência de justiça".

O ser humano foi criado à imagem de Deus. o que implica atributo e atribuição. Pela incredulidade, o ser humano perde essa imagem como atribuição, ficando preservada sua imagem como atributo, a qual é imperdível, indelével. ${ }^{61} \mathrm{~A}$ incredulidade se expressa em não mais confiar na providência e promissão de Deus, que tudo criou e viu que era bom, mas gloriar-se de si mesmo. A incredulidade, como pecado original é, para Lutero, o afastamento, a separação do ser humano de Deus. Pelo pecado, Adão se afastou de Eva, Eva de Adão e ambos, de Deus. Pelo pecado, se encurvaram em si mesmos, construindo outros deuses. A incredulidade tornou o ser humano fábrica e fabricante de imagens, portanto idólatra. Ele abandonou seu papel de cooperador de Deus nos estamentos e, pelo pecado, pretendeu ser cocriador e consumidor dos próprios ídolos. ${ }^{62}$

\section{Matrimônio e a esperança de vida}

Lutero compreende o Evangelho de Jesus Cristo como restaurador da imagem de Deus no ser humano. Ainda que a mente e a vontade permaneçam viciadas (imagem como atribuição), a partir de Cristo, a imagem de Deus é restaurada no ser humano, isto é, uma "imagem melhor", renascida "[...] para a vida eterna, ou melhor, para a esperança da vida eterna, pela fé, para que vivamos em e com Deus e sejamos um com ele, como diz Cristo" ${ }^{63}$. O renascimento para a vida - Lutero contrapõe morte e vida! ${ }^{64}$ - é também renascimento para a justiça. Restauração para a esperança de vida é também libertação e renascimento para a justiça, que inicia nesta vida. ${ }^{65}$

Qual é a justiça original? [...] a justiça original significa que o ser humano era justo, verdadeiro, reto e não só de corpo, mas especialmente de alma, que reconheceu a Deus, obedeceu-lhe com a maior alegria, compreendeu as suas obras, sem ter sido instruído. ${ }^{66}$

Pecado original e justiça original, portanto, precisam ser concebidos de forma inter-relacionada: "[...] o pecado original mostra o que é a justiça original, e vice-versa; que o pecado original é a perda ou a privação da justiça original, assim como a cegueira é a privação da visão" ${ }^{\text {67 }}$. Por sua vez, "[...] a raiz e a fonte do pecado são a

${ }^{61}$ Segundo Brakemeier, para Lutero, imagem e semelhança são sinônimos. BRAKEMEIER, Gottfried. $O$ Ser Humano em Busca de Identidade; Contribuições para uma antropologia teológica. São Leopoldo: Sinodal; São Paulo: Paulus, 2002. p. 24-25, 44-45.

62 BAYER, 2007, p. 114-115, 125, 128.

${ }^{63}$ LUTERO, 2014, p. 105.

${ }^{64}$ ASENDORF, 1998, p. 78.

${ }^{65}$ LUTERO, 2014, p. 105; FORELL, 1977, p. 86-88.

${ }^{66}$ LUTERO, 2014, p. 143.

${ }^{67}$ LUTERO, 2014, p. 144. Ver também p. 191. 
incredulidade e o afastamento de Deus, exatamente como a fé, por seu turno, é a fonte e a raiz da justiça" ${ }^{68}$.

Lutero percebe que, pelo matrimônio, o ser humano é remetido à vida e à justiça originais do jardim do Éden. Concretamente, isso significa a consciência de comunidade, companheirismo, mutualidade, reciprocidade do amor, dignidade e igualdade entre mulheres e homens. Inversamente, a moral monástica medieval é, para Lutero, afirmação do próprio pecado original. ${ }^{69}$ A moral monástica do celibato é obra diabólica (separação, afastamento) que leva à morte. Ela potencializa a não vida, por isso é abominada por Deus. Deus “[...] quer que os seres humanos se multipliquem na terra. [...] Pois sua vontade é a vida, e não a morte. [...] Deus não ama a morte, mas a vida, exatamente como, no início, também criou o ser humano não para que morresse, mas exatamente vivesse: 'Mas a morte entrou no mundo mediante a inveja do diabo' [Sab 2.24]"70.

Nessa perspectiva, Lutero resgata a bênção da maternidade, exaltando o papel da mulher, afirmando que "[...] todos nós somos concebidos por elas, nascemos delas e somos aquecidos por elas" ". O renascimento para a esperança de vida é proclamado por Deus que chama Eva "[...] de Eva para que esse nome sirva como lembrete da promessa, a partir da qual ele ${ }^{72}$ próprio também reviveu, e deixe a esperança de vida eterna aos descendentes"73.

A “esperança de vida" é instrumentalizada e concretizada por Deus em sua promessa a Eva e por meio de Eva: “[...] de que dela virá a semente que esmagará a cabeça de Satanás"74. Deus se vale de forma especial da mulher para a bênção: "[...] para Deus não teria sido difícil ou impossível trazer seu Filho ao mundo sem uma mãe, mas, mesmo assim, ele quis valer-se do sexo feminino. [...] quis que seu Filho fosse concebido no útero de uma mulher, fosse gestado e nascesse, não formado a partir da argila nem gerado por um homem"75.

A esperança de vida encontra sua razão na própria fé em Cristo, que negou à morte sua palavra última: “[...] se permanecermos na fé, a nossa morte é uma clara oportunidade para a vida"76. Por isso "esse é o poder da fé, que medeia entre a morte e a vida e transforma morte em vida [...]"77. "[...] a fé consegue conciliar opostos, e não é uma qualidade ociosa [...]. Ela tem o poder de matar a morte, condenar o inferno, ser pecado para o pecado, um diabo para o diabo, de tal modo que a morte não seja morte, embora a percepção de todos ateste que a morte está presente." ${ }^{\prime 78}$

A fé confere a certeza de que

\footnotetext{
${ }^{68}$ LUTERO, 2014, p. 185.

${ }^{69}$ LINDBERG, 2001, p. 126-127, 430; JUNGHANS, 2001, p. 76-77.

${ }^{70}$ LUTERO, 2014, p. 332.

71 LUTERO, 2014, p. 218.

72 Lutero refere-se aqui à encarnação de Deus em Cristo por meio de Maria.

${ }^{73}$ LUTERO, 2014, p. 237.

${ }^{74}$ LUTERO, 2014, p. 215.

75 LUTERO, 2014, p. 516.

${ }^{76}$ LUTERO, 2014, p. 338.

77 LUTERO, 2014, p. 481; ASENDORF, 1998, p. 231-232.

${ }^{78}$ LUTERO, 2014, p. 482.
} 
[...] a morte não te destruirá, mas será impulso e auxílio para a vida.

[...] Portanto, quaisquer que sejam as desgraças, das quais esta vida tem inúmeras e com as quais tanto nossos bens como nossos corpos são infestados, transformar-se-ão em salvação e alegria se estiveres na arca, isto é, se creres e te apoderares das promessas feitas em Cristo, pois é necessário que a morte, que te arrebata, se transforme em vida, e que o inferno, que te engole, se transforme em caminho para o céu ${ }^{79}$.

A esperança de vida é conferida no batismo, pelo qual o ser humano é restituído "[....] a uma vida de esperança, ou melhor, a uma esperança de vida" ${ }^{80}$. Pelo batismo, em Cristo, o ser humano é restaurado coram Deo, coram seipso, coram hominibus e coram mundo, para realizar a justiça de Deus como esperança de vida.

\section{Conclusão}

Lutero identifica no relato da criação em Gênesis que Deus tudo criou e viu que era bom. O pecado não tem sentido de "pecado moral", mas como o germe da morte. Em Jesus Cristo, Deus reafirma seu projeto original da vida. A cruz de Cristo reúne ambos: pecado e justiça originais. Ela desmascara o ser humano centrado em sua própria justiça e lhe presenteia a justiça de Deus revelada em Cristo. Em condição de excentricidade radical, isto é, cristocentricidade, é tornado cooperador da justiça de Deus. De criador e fabricante de imagens, é tornado servidor, cooperador.

O matrimônio constitui-se em chance dada por Deus para superar a vida egocentrada. Por essa razão, Lutero rompe com a compreensão dicotômica (ou tricotômica) de corpo e alma (e espírito), que nega a corporeidade em favor de uma suposta elevação e salvação da alma, e concebe homem e mulher a partir da responsabilidade socioeconômica. O matrimônio, no pensamento do reformador, carrega consigo sinais do que era a justiça original no jardim do Éden, pois radicaliza a existência do ser humano "diante de", "face a", "na presença de": coram Deo, coram meipso, coram hominibus e coram mundo. Esse coram se expressa em duplo percurso: fé (coram Deo) e amor (coram mundo). Pela fé e pelo amor o coram exclui toda possibilidade de uma existência estática, egocentrada. Pelo contrário, implica a existência dinâmica, isto é, coexistência, vida cooperativa. A coexistência, por sua vez, implica a confissão última de que Deus tudo criou e deseja a vida.

A afirmação da vida é, no pensamento de Lutero, afirmação do próprio matrimônio, como espaço da produção e reprodução da vida (oeconomia). Por essa razão, homem e mulher são feitos companheiros na boa economia de Deus. Produção, no sentido da criação como "hospedagem" pela qual Deus providencia sustento, e reprodução, no sentido da sexualidade pela qual a espécie humana é preservada, são expressão de graça, gratuidade. $\mathrm{O}$ reconhecimento da economia como graça coloca

${ }^{79}$ LUTERO, 2014, p. 339.

${ }^{80}$ LUTERO, 2014, p. 213. 
o ser humano coram Deo em culto de gratidão e o justifica para ser justiça de Deus coram mundo.

\section{Referências}

ASENDORF, Ulrich. Lectura in Biblia; Luthers Genesisvorlesung (1535-1545). Göttingen: Vandenhoeck \& Ruprecht, 1998.

BRAKEMEIER, Gottfried. O Ser Humano em Busca de Identidade; Contribuições para uma antropologia teológica. São Leopoldo: Sinodal; São Paulo: Paulus, 2002.

BAYER, Oswald. A Teologia de Martim Lutero; uma atualização. São Leopoldo: Sinodal, 2007. DEIFELT, Wanda. Da cruz à árvore da vida: epistemologia, violência e sexualidade. In: NEUENFELDT, Elaine; BERGESCH, Karen; PARLOW, Mara (Orgs.). Epistemologia, Violência e Sexualidade. Olhares do II Congresso Latino Americano de Gênero e Religião. São Leopoldo: Sinodal; EST, 2015.p. 13-30. Disponível em: $<$ http://www.est.edu.br/downloads/ppg/bibliografia/ Epistemologia_Violencia_Sexualidade.pdf $>$. Acesso em: 24 abr. 2019

DIETZ, Martin Timóteo. Amor em Lutero; Perspectivas a partir da explicação dos mandamentos. In: BRÍGIDO, Maria Aparecida da Silveira; HERBES, Nilton Eliseu; HEIMANN, Thomas (Orgs.). Amor em Relação; Reflexões sobre o amor numa perspectiva multidisciplinar. São Leopoldo: Sinodal; EST, 2018. p. 77-88.

EBELING, Gerhard. O Pensamento de Lutero. São Leopoldo: Sinodal, 1988.

FORELL, George W. Fé Ativa no Amor. Porto Alegre: Concórdia; São Leopoldo: Sinodal, 1977.

JUNGHANS, Helmar. Temas da Teologia de Lutero. São Leopoldo: Sinodal, 2001.

LINDBERG, Carter. As Reformas na Europa. São Leopoldo: Sinodal, 2001.

LOEWENICH, Walther von. A Teologia da Cruz de Lutero. São Leopoldo: Sinodal, 1988.

LUTERO, Martinho. Da Vida Matrimonial. In: . Obras Selecionadas. São Leopoldo:

Sinodal; Porto Alegre: Concórdia, 1995. v. 5, p. $\overline{161-183 .}$

LUTERO, Martinho. O Debate de Heidelberg. In:

Sinodal; Porto Alegre: Concórdia, 1987. v. 1, p. 35-54.

Obras Selecionadas. São Leopoldo:

LUTERO, Martinho. O Magnificat; traduzido e explicado pelo Dr. Martinho Lutero, agostiniano. In: _. Obras Selecionadas. São Leopoldo: Sinodal; Porto Alegre: Concórdia, 1996. v. 6, p. $20-78$.

LUTERO, Martinho. Prefácio à Epístola de S. Paulo aos Romanos. In: . Obras Selecionadas. São Leopoldo: Sinodal; Porto Alegre: Concórdia, 2003. v. 8, p. 129-141.

LUTERO, Martinho. Preleção sobre Gênesis. In: Obras Selecionadas. São Leopoldo: Sinodal; Porto Alegre: Concórdia; Canoas: Ulbra, 2014. v. 12, p. 53-530.

PINOMAA, Lennart. Sieg des Glaubens; Grundlinien der Theologie Luthers. Göttingen: Vandenhoeck \& Ruprecht, 1964.

PRIEN, Hans-Jürgen. Luthers Wirtschaftethik. Göttingen: Vandenhoeck \& Ruprecht, 1992.

WESTHELLE, Vítor. Poder e Política - incursões na teologia de Lutero. In: HELMER, Christine. Lutero: um teólogo para tempos modernos. São Leopoldo: Sinodal; EST, 2013. p. 315-331. 